WellBeing International

WBI Studies Repository

1985

\title{
Recognition and Alleviation of Pain in Animals
}

\author{
P. A. Flecknell \\ University of Newcastle-upon-Tyne
}

Follow this and additional works at: https://www.wellbeingintlstudiesrepository.org/acwp_awap

Part of the Animal Studies Commons, Comparative Psychology Commons, and the Other Animal Sciences Commons

\section{Recommended Citation}

Flecknell, P.A. (1985). Recognition and alleviation of pain in animals. In M.W. Fox \& L.D. Mickley (Eds.), Advances in animal welfare science 1985/86 (pp. 61-77). Washington, DC: The Humane Society of the United States.

This material is brought to you for free and open access by WellBeing International. It has been accepted for inclusion by an authorized administrator of the WBI Studies Repository. For more information, please contact wbisr-info@wellbeingintl.org.

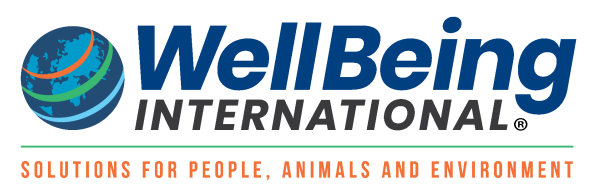




\section{RECOGNITION AND ALLEVIATION OF PAIN IN ANIMALS}

\section{P.A. Flecknell}

University of Newcastle upon Tyne

Comparative Biology Centre

The Medical School

Framlington Place

Newcastle upon Tyne NE2 $4 \mathrm{HH}$

United Kingdom

\section{Introduction}

The pain and distress which animals experience as a consequence of their use by man figures prominently in discussions of animal welfare. Some improvements have been made in animal housing and husbandry practices and it is likely that further progress will be made in this field. In comparison, relatively little attention has been given to the problem of minimizing the pain and distress caused to animals by the various procedures to which they are subjected. The most publicized of these are the wide range of experimental techniques which are undertaken using laboratory animals, but also includes procedures such as castration of farm animals and neutering operations carried out on pet animals. The prevention or alleviation of the pain associated with such procedures is a complex problem with no single, simple solution. Consideration must be given to the use of analgesic drugs, the provision of high standards of general care, and the use of special nursing techniques. When dealing with post-operative care, the pre-operative management of the animal, the operative procedures and the anesthetic regime must all be evaluated and, when necessary, modified to minimize pain or discomfort.

\section{Pain Perception in Animals}

It is generally accepted that animals perceive and react to pain in a manner similar to man, although the conscious experience of pain may 
well vary in different animal species and man (Melzack and Dennis 1980; Moloney 1985). Our inability to define precisely the nature of the sensation of pain leads to difficulties, both in its assessment and in recommending methods of pain relief. In man, the common assessment of pain is based mostly on the subjective criterion that "pain is what the patient says hurts" (Smith 1984). In animals, a variety of definitions has been proposed, however as yet none of these are entirely satisfactory (Uvarov 1985).

Although pain is more easily detected in man than in animals, the standard of pain relief following surgery in man is generally poor, with some 40-50 percent of patients receiving inadequate analgesia following surgery (Smith 1984). In a recent survey of the incidence of post-operative pain in children, only 25 percent were found to be pain-free immediately following surgery (Mather and Mackie 1983). In seems reasonable to assume that given the additional difficulties of detection of pain, and the generally lower level of nursing care, that an even greater percentage of animals will experience post-operative pain. The failure to provide adequate pain relief in man has been attributed to a number of factors, including a lack of awareness of the problem by the medical staff concerned and a fear of the undesirable side-effects, such as respiratory depression, which are associated with the use of opiates. It seems likely that similar factors are involved in the provision of pain relief in animals.

If the standard of pain relief for animals is to be improved, it is important to ensure that the possibility of pain in animals is acknowledged, that the staff concerned are trained to recognize pain and distress in animals, and that effective methods of pain relief are employed wherever possible.

In addition to the desirability of relieving pain on humane grounds, pain also has other adverse effects, for example, movement is restricted and food and water intake are depressed. Pain has also been shown to cause widespread vasoconstriction and perpetuate the metabolic and hormonal changes induced by surgery (Kehlet 1978).

\section{Recognition of Pain in Animals}

The response of animals to pain varies considerably and it is difficult to offer definitive criteria for the assessment of pain in different animal species. There are, however, a range of behavioral changes that are frequently associated with pain and these are often helpful in determining its degree and thus whether analgesics are required.

In general, animals which are in pain are relatively inactive and may remain completely immobile within their cage or pen. When observed undisturbed, alterations in the pattern or rate of respiration 
may be noted, and on examination the heart rate may be elevated. If the animal moves it will often have an abnormal gait and when approached or handled may be uncharacteristically aggressive. If the painful area is confined to one limb joint or to a surgical wound, then the animal will usually attempt to prevent the area from being handled and may react violently to attempts to manipulate it. When left undisturbed, the animal may position itself to observe the painful area, and may lick or groom the area excessively. Alternatively, normal grooming behavior may be absent, and as a consequence the coat may appear dirty and unkempt.

Pain may cause the adoption of an abnormal posture, for example a "tucked up" appearance produced by tensing the muscles of the abdomen and back. Animals may also become unusually restless, moving about constantly, or continuously getting up and laying down. Very abnormal behavior such as flailing or extensor rigidity of the limbs, writhing or production of self-inflicted bite wounds, indicates severe pain. Similar behavior may, of course, occur in the immediate post-operative period during recovery from anesthesia, before the animal becomes fully conscious. If, however, such behavior persists when the animal has fully recovered from the anesthetic, then it must be assumed to be experiencing severe pain which must be relieved. If such pain cannot be alleviated rapidly, a decision must be taken as to whether the animal should be humanely killed immediately.

Animals in pain frequently reduce their food and water intake, often to the extent that serious dehydration occurs. If pain persists for a prolonged period, the reduction in food and water intake will result in a fall in body weight which may be a useful index for the assessment of chronic pain, and also for monitoring the efficacy of any analgesia.

Abnormal vocalization may occur-dogs may whine or whimper, cats miaow and cry, or occasionally may purr, rats squeak at an unusual pitch, and primates may scream or grunt when moving. It must be appreciated that vocalization may be elicited in response to non-painful stimuli. For example, the squeals of pigs in response to handling, or in anticipation of feeding, might be interpreted as indicative of pain by those unfamiliar with the normal behavior of the species.

All of the criteria above must be considered in conjunction with the nature of any surgical procedure which has been undertaken, or the characteristics of any disease processes which may be present. As mentioned above, it is also important to be aware of the normal behavioral characteristics of the particular animal species. It is especially useful to discuss the appearance of an individual animal with its owner or handler, since many of the changes in demeanor may be extremely subtle, and apparent only to someone who is very familiar with the animal's previous behavior.

The clinical assessment of pain, distress, and discomfort has been described in small mammals (Morton 1985), dogs and cats (Taylor 1985), 
horses (Silver 1985), ruminants (Edwards 1985), pigs (Oldham 1985), poultry and birds (Gentle 1985), primates (Tribe 1985), and fish (Brown 1985).

A technique for assessing pain by means of a scoring system based on clinical observation has been described by Morton and Griffiths (1985). The assessment system catalogues a range of clinical signs such as reduced food and water intake, altered posture, change in temperament, and altered respiration and pulse rate. Deviations of these signs from normal are scored according to the severity of the deviation. The total score from all of the listed clinical signs provides an overall assessment of the animal, a high score indicating that pain or distress is likely to be present. This proposed scoring system utilizes many clinical signs that could be produced by other, non-painful factors. Despite this drawback, an animal which has a high score is quite obviously abnormal, and should receive careful attention.

When considering chronic pain of gradual onset, many of the behavioral changes may be ascribed to other factors. A pet dog with a tumor may be thought lethargic and depressed as a consequence of natural aging rather than the pain caused by the tumor. Administration of an analgesic to such animals may result in a marked improvement in its "quality of life" (Yoxall 1978).

It is apparent that although the behavior of animals in pain may be dramatic, in some the response may be so slight as to be almost inapparent to all but those most familiar with the behavior patterns both of the animal species involved, and of the individual animal. Such familiarity is difficult to achieve, and in many instances there will be considerable doubt as to whether an animal is in pain. For this reason it is the author's practice to assume that a procedure or injury which is likely to cause pain in man will also cause pain in an animal. Such anthropomorphic views are open to criticism, and ignore the issue of what significance the animal attaches to its pain. It is possible that the apparent tolerance of injuries that would be acutely painful in man may involve a greater suppression of central pain perception in some animal species. Until unequivocal evidence is produced to support such views, it is obviously more humane to assume that pain is present, and to make every attempt to provide effective pain relief.

\section{Pain Relief in Animals}

In most instances pain relief will be provided by the use of analgesic drugs. Although the use of such agents will control pain, an animal may still exhibit signs of distress. Semantic difficulties abound in the field of animal welfare, and numerous definitions of stress and distress have been proposed. In this paper the term "distress" is used to describe the state produced by adverse factors which would not usually be considered 
to cause pain, but are certainly unpleasant and should be avoided. For example, a cold, wet environment, devoid of suitable bedding material is likely to cause distress to some animal species. Similarly, states of physiological imbalance, such as dehydration caused by inadequate fluid therapy, would not be referred to as painful, but would cause distress. It seems reasonable to include methods aimed at reducing distress in the management of pain. It is also assumed by the author that pain and distress can be heightened by fear or apprehension, and any regime of nursing care must include reassurance and calming of the animal, either by personal contact, environmental manipulations, or by pharmacological means. In addition to analgesics, a range of other drugs including tranquilizers, sedatives, and corticosteroids or similar agents with anti-inflammatory activity may all play a role in the management of pain.

\section{Analgesic Drugs}

Of the wide variety of analgesics available for use in man, relatively few have been employed in routine veterinary clinical practice. A certain amount of published information concerning the suitability of analgesics for veterinary use is available, and in many instances the original assessment of a drug's properties in experimental animals provides useful data (Flecknell 1984).

\section{Centrally Acting Analgesics}

\section{Narcotics: Agonists}

This group of drugs includes the best established veterinary analgesics pethidine (meperidine) and morphine. All are potent analgesics but also produce some undesirable effects on the central nervous system, respiratory depression being of the most clinical significance. Most of the side-effects can be reversed by the use of specific antagonists (see below), although this will, of course, reverse any analgesia which has been produced.

\section{Morphine}

Morphine has been used in veterinary practice in the United Kingdom for some years (Hall and Clarke 1983), and its efficacy in the dog has been recently confirmed by Taylor and Houlton (1984). It is an effective analgesic in a wide range of species (table 1), but its undesirable side-effects can include severe respiratory depression and overdosage can cause incoordination or excitement in some species (cat, Davis and 
Donnelly 1968, Lumb and Jones 1984; mouse, Pearl et al. 1969, Lumb and Jones 1984) or narcosis in others (dog, primate, rabbit, Lumb and Jones 1984).

\section{Pethidine (Meperidine)}

This drug is perhaps the most widely used veterinary analgesic and suitable dose rates have been established for a range of species (table 1), although its respiratory depressant effect can limit its use, particularly in the immediate post-operative period. In addition, pethidine has a relatively short duration of action in some species, for example, less than two hours in the cat (Davis and Donnelly 1968).

\section{Methadone}

Clinical use of methadone in the dog has been largely restricted to pre-anesthetic medication $\left(1 \mathrm{mg} / \mathrm{kg}, \mathrm{i} / \mathrm{v}\right.$ or $\mathrm{s} / \mathrm{c}^{*}$ ) (Lumb and Jones 1984). In the horse, in combination with acepromazine $(50 \mathrm{mg}$ methadone and $50 \mathrm{mg}$ acepromazine total dose/1000 lb horse), it has been reported to provide effective sedation (Schauffler 1969). The analgesic action of the drug in horses appears variable, although some beneficial effect could be demonstrated (Pippi and Lumb 1979).

\section{D-Propoxyphene}

D-Propoxyphene is structurally related to methadone, but has considerably less analgesic potency. It has been recommended for the relief of mild to moderate pain in the dog at a suggested dose of $16.25 \mathrm{mg}$ b.i.d. per os** for small dogs, up to $32 \mathrm{mg} / \mathrm{kg}$ t.i.d. $\dagger$ for larger breeds (Yoxall 1978). In the author's experience it is useful at these dose rates for the relief of musculoskeletal pain in this species.

\section{Codeine and dihydrocodeine}

These two morphine derivatives have been used to a limited extent in small animals. Oral preparations of codeine may be of use for the control of mild pain in the dog at a dose of $2 \mathrm{mg} / \mathrm{kg}$ (Taylor 1985).

\section{Fentanyl and etorphine}

Fentanyl and etorphine are two extremely potent analgesics which have been widely used as components of neuroleptanalgesics, and their use for this purpose has been reviewed by Green (1979). The short

\footnotetext{
$* \mathrm{i} / \mathrm{v}$-by intravenous injection

s/c-subcutaneous injection

*** b.i.d. per os - twice a day by mouth

$\dagger$ t.i.d. - three times a day.
} 
duration of action of fentanyl limits its value as an analgesic when given by intermittent injection, but it is potentially useful for administration by continuous intravenous infusion (see later).

\section{New Opiates}

Alfentanil resembles fentanyl in almost all its pharmacological and clinical effects. It differs in having a very short duration of action (about ten minutes in the rat, Niemegeers 1977), making it especially suitable for administration by continuous intravenous infusion.

Lofentanil, a novel, extremely potent narcotic analgesic, has the longest duration of action of any drug of this group so far discovered. It appears unlikely that the drug will be introduced into human clinical practice, but a drug having such a long duration of action might prove extremely useful in providing analgesia in animals.

Carfentanil, another member of the fentanyl group of analgesics, has a potency thirty-two times that of fentanyl (i.e., about 18,000 times as potent as pethidine). It has been used for the immobilization of wild animals where its high potency enables its use in low volumes $(<1 \mathrm{~m} 1$ for most large animals, De Vos 1978). It has also been used in combination with etomidate as an anesthetic in guinea pigs (Neumann et al. 1980).

\section{Narcotics: Partial Agonists}

This group of drugs has mixed morphine-like analgesic and antagonist properties. They were developed primarily in an attempt to produce analgesic drugs free from morphine's undesirable side-effects, and in particular to avoid the problem of the development of addiction.

\section{Pentazocine}

Pentazocine has been used to a limited extent in veterinary clinical practice. Its use in the dog to control post-operative pain has been reported by Cooper and Organ (1977) and Taylor and Houlton (1984). It is the author's experience that it can be used effectively to relieve acute pain in nonhuman primates (table 1).

\section{Buprenorphine}

This potent, long-lasting analgesic appears to offer several advantages compared to many of the agents mentioned above. Although controlled studies in animals are limited to experimental data in rodents (Heel et al. 1979; Cowan et al. 1977a, 1977b) and a clinical trial in the dog (Taylor and Houlton 1984), the drug has been used clinically in both laboratory and companion animals. Its use in the horse has been reported by Hall and Clarke (1983), and it has been used to provide effective pain relief in a wide range of species by the author (table 1 ). 
Buprenorphine's efficacy in producing pain relief following acute trauma or surgery has also been established in small animal practice in the United Kingdom.

This drug has a considerably longer duration action in most species ( $>8$ hours) than the other agents described above. In addition, it seems to produce fewer and less marked side-effects.

\section{Butorphanol}

This drug has similar pharmacological properties to pentazocine (House 1979), but a somewhat greater potency (Heel et al. 1978). Information concerning its effects in animals is limited (Pircio et al. 1976). Its administration to the horse has been described by Robertson et al. (1981), although its analgesic effects were not evaluated.

\section{Nalbuphine}

Nalbuphine has proven to be an efffective analgesic in acute and chronic painful conditions in man, with fewer undesirable side-effects than morphine. Its analgesic action has been studied in mice and rats (Blumberg et al. 1968), however, it would appear to be a potentially useful drug in the dog, since in this species the plasma half-life is 8.3 hours (Fahmy 1983), suggesting that the agent may produce long-lasting analgesia.

\section{Other Analgesic Drugs}

A range of low to moderate potency compounds such as aspirin, paracetamol (acetaminophen), and phenacetin are widely used in man to control mild pain. Their use in veterinary practice is limited but these compounds are often administered to pet animals by their owners. Such uncontrolled administration can have serious consequences. Aspirin and paracetamol may both be rapidly and fatally toxic to cats (Wilkinson 1984). In dogs, aspirin is extremely irritant to the gastric mucosa (Davison et al. 1966) and it is preferable to use other preparations such as paracetamol and codeine in this species.

\section{Anti-Inflammatory Agents}

Corticosteroids are the drugs most widely used in veterinary practice for the reduction of chronic or acute inflammatory responses. By reducing the degree of inflammation, they diminish the pain associated with such a reaction, but have no specific analgesic action. They are useful in treating conditions in which pain is the result of tissue inflammation. However, since the inflammatory response is a prerequisite for successful healing of damaged tissue, they must be used with caution. 
A number of non-steroidal anti-inflammatory drugs have been developed, the most widely used in veterinary practice being phenylbutazone. Phenylbutazone has proven particularly useful in the control of musculoskeletal pain in the dog and the horse, however, its numerous undesirable side-effects may limit its use (Yoxall 1978). Other drugs have been introduced into human clinical practice, and some of these have been used in veterinary practice in the United Kingdom (Taylor 1985). Ibruprofen has been recommended for use in the dog, an initial loading dose of $30 \mathrm{mg} / \mathrm{kg}$ per $\mathrm{os}^{*}$ in divided doses, followed by a maintenance dose of $16 \mathrm{mg} / \mathrm{kg}$ being suggested by Yoxall (1978).

\section{Tranquilizers}

This group of drugs has no intrinsic analgesic action, and when used alone they may actually increase pain perception. When administered in conjunction with a narcotic analgesic they will potentiate the effects of the latter. The combination of sedation, analgesia, and a reduction in fear and apprehension is extremely useful, particularly immediately following surgery or trauma. The degree of sedation produced varies considerably in different animal species, for example, diazepam, a sedative which can be used to induce hypnosis (sleep) in man, has little sedative action in the dog, but in rodents and rabbits it produces marked sedation.

\section{Clinical Use of Analgesics}

As has been indicated above, the use of analgesics in animals is hampered by the lack of information concerning suitable dose rates and by practical problems associated with drug administration. A major problem with most analgesics is their short duration of action (1-4 hours), so that maintenance of adequate analgesia requires repeated administration of the drug, which is often difficult to arrange in practice. Buprenorphine, unlike other narcotic analgesics, has been shown to have a duration of action of at least 10-14 hours in both animals and man. Veterinary clinical use of this agent has shown that it is effective in controlling severe post-operative pain for at least 10-14 hours. Since buprenorphine has some narcotic antagonistic activity, it can be used to reverse the narcosis produced by neuroleptanalgesic combinations (e.g., fentanyl/fluanisone and fentanyl/droperidol) and yet maintain effective post-operative analgesia.

Slow release preparations of analgesics have been developed for experimental use, (Laska and Fennessy 1978; Frederickson and Smiths

\footnotetext{
per os-by mouth
} 
1973; McGinity and Mehta 1978), and it would seem feasible to adapt such techniques to provide long-term analgesia. A slow-release morphine preparation for oral administration has become available in the United Kingdom (MST Continus; Napp Laboratories Ltd.), and has been shown to provide up to six hours pain relief in man (Fell et al. 1982). A sustainedrelease morphine preparation for intramuscular or subcutaneous injection is also marketed (Duromorph, LAB Ltd.), however, no information is available concerning the use of either of these products in animals, although they would appear to be potentially useful preparations.

An alternative method of providing effective pain relief is to use a continuous drug delivery system such as a chronically implanted catheter and a suitable swivel apparatus. The use of continuous intravenous infusion of opiates has been evaluated clinically in man (see review by Mather 1983) and shown to be considerably more effective in providing pain relief than intermittent injections. When using the intravenous route, administration of a drug such as alfentanil, with a short duration of action, enables rapid variation in plasma concentrations should undesirable side-effects occur. In most animal applications, however, the technique will be used to provide analgesia for prolonged periods (for example, overnight) in the absence of nursing staff. Under these circumstances, the main factors influencing the choice of drug will be its therapeutic index and the volume of solution required. If the volume of drug required is small, a light-weight portable infusion pump can be used, bandaged directly to the animal. It is also usually more convenient to use the subcutaneous route of administration. Although this does not enable rapid variations in plasma levels to be achieved should undesirable side-effects occur, it is a much easier technique to instigate and maintain.

When calculating the dose rates required, as a general guide, following administration of an initial standard dose, the quantity of drug needed for continuous infusion will be about half that which would be given by intermittent injection. The animal should, of course, be observed carefully to determine that effective analgesia is being acheived and that undesirable effects, such as respiratory depression, are minimal. When pharmacokinetic data are available for the drug and the animal species concerned, more accurate estimation of infusion rates are possible, and these techniques are reviewed by Mather (1983).

\section{Undesirable Effects of Narcotic Analgesics}

Excessive doses of narcotic analgesics can cause severe respiratory depression, requiring assisted ventilation or reversal with an antagonist such as naloxone. Opiate antagonists, of course, reverse any analgesia that has been produced as well as reversing the respiratory 
depression, so that it may be preferable to use a specific respiratory stimulant such as doxapram. Doxapram has a relatively short duration of action (fifteen to twenty minutes), and either repeated doses or a continuous infusion of the drug may be needed to maintain adequate stimulation of respiration. Use of buprenorphine in animals appears to carry little risk of producing respiratory depression. However, if this does occur, doxapram should be used since naloxone is relatively ineffective in reversing the depressant effects of buprenorphine.

Paradoxically, the potent action of narcotics in abolishing pain has been cited as a disadvantage of their use in clinical veterinary practice. Pain, of course, serves a protective function in discouraging movement of a traumatized area, and so tending to minimize further injury. Complete abolition of pain in the post-operative period has been suggested as likely to lead to disruption of sutures by excessive activity. This is rarely, if ever, a problem providing good wound closure techniques have been used. Excessive activity can be controlled, if necessary, by the addition of a tranquilizer to the post-operative drug regime, and use of appropriate bandaging and splinting techniques can provide additional wound support.

It is the author's view that analgesics should never be withheld on such grounds as those described above. Clinical experience has shown that effective use of analgesics, rather than resulting in tissue damage due to excessive activity, will often prevent undue self-trauma of the affected area.

\section{Additional Components of the Management of Pain}

The control of pain requires more than simply the administration of an appropriate analgesic. If a surgical procedure is to be undertaken, it may be useful to include an opiate such as pethidine in any preanesthetic medication to provide pain relief in the immediate post-operative period. If surgery is prolonged, however ( $>2$ hours), the analgesic effects of the drug will no longer be apparent and a period of acute pain may follow emergence from the anesthetic, unless prompt administration of an analgesic is ensured. This may be avoided to some extent by the use of an anesthetic agent such as methoxyflurane which has been shown to have limited analgesic properties in the post-operative period (Vickers et al. 1984). Alternatively, the technique of reversal of a neuroleptanalgesic combination with a partial agonist such as buprenorphine can be used to try to ensure a completely pain-free emergence from anesthesia.

The pain caused by surgical procedures can, of course, be reduced by good technique, particularly that directed at minimizing tissue trauma. 
Preventing tension on suture lines, immobilizing fractures and traumatized tissue, and padding and protecting surgical wounds considerably reduces post-operative pain.

Provision of a special area for recovery from anesthesia and for post-operative nursing is of importance. This enables more appropriate environmental conditions to be maintained and encourages individual attention and special nursing-all important factors in minimizing pain and discomfort.

Such an area should be warm (approximately 25-30 degrees Centigrade for adult animals of most species), draught-free, and quiet. Hypothermia is a common problem during post-operative recovery and a heating pad or heating lamp may be required to provide additional warmth. It is also useful to reduce heat losses by insulating the animal by providing additional bedding materials and by use of specialized blankets. Body temperature should be monitored to ensure that the measures employed are effective, and also to avoid overheating and consequent hyperthermia. Fluid intake is frequently reduced post-operatively so that where appropriate oral intake should be encouraged and hand feeding of fluids undertaken whenever necessary. If these simple measures prove inadequate, dehydration must be corrected by parenteral administration of fluids. Food intake should also be monitored carefully, and supplemented by hand feeding if required.

In all species, every effort should be made to keep the animal clean and dry, since this is more comfortable for the animal and encourages closer attention from the nursing staff. There is little point in preventing pain by the use of analgesics if the animal is uncomfortable and distressed by inappropriate or inadequate post-operative care.

If an animal appears apprehensive, reassurance by personal contact will be effective only in animals which are accustomed to such attentions. Even in these species, and certainly in the case of many laboratory species, use of tranquilizers may be considered necessary.

\section{Future Development}

In man, a range of new approaches to the management of pain are being developed. Whilst many of these are unlikely to be routinely used in animals, others hold considerable promise. One technique that may prove particularly useful is the administration of opiates by the intrathecal or epidural routes. This technique has been employed clinically in man and extensively investigated in experimental animals (see reviews by Yaksh 1981, 1983). The technique involves implantation of an epidural or intrathecal catheter to allow repeated administration of small quantities of opiates such as morphine. Profound, long-lasting 
analgesia is produced, for example, 12-16 hours following intrathecal morphine in primates (Yaksh 1981). The areas of the body rendered analgesic depend upon the spinal cord level reached by the opiate. In most instances the technique has been used to produce analgesia of the abdomen and hindquarters, although successful production of analgesia extending to the forelegs in the dog has been reported by Cohen et al. (1982). In man the technique has been used to control pain following a variety of abdominal surgical procedures, lower limb surgery, and thoracotomy (Camporesi and Redick 1983). The analgesia produced by epidural and intrathecal opiates is not associated with any loss of motor function or loss of sensation to touch, unlike the effects produced by local anesthetics administered by the same routes.

The lower doses of drug used cause few of the systemic effects such as sedation, which develop following intramuscular injection of opiates. Although some undesirable side-effects have been noted including pruritis (Hales 1980) and urinary retention, the latter does not appear to be a problem in animals. The most significant side-effect in man has been the development of severe respiratory depression. The incidence of this problem is difficult to assess, but is certainly low ( $<0.5$ percent, Reiz et al. 1981; Gustafsson et al. 1982) and has not been noted as a serious side-effect in the limited clinical or experimental studies in the $\operatorname{dog}$ (Bonath et al. 1984; Cohen et al. 1982). Repeated intrathecal administration of opiates and maintenance of spinal catheters for prolonged periods (4-16 months) in primates resulted in no demonstrable neurological or pathological changes (Yaksh 1981). It is clear that this technique could be employed in a wide range of situations in animals, particularly following experimental surgical procedures. It might also offer a method of producing long-term analgesia for localized disease processes, or chronic inflammatory conditions. The method of catheter implantation has been described in a wide range of species including the rat (Yaksh and Rudy 1976), the rabbit (Yaksh and Rudy 1976), the cat (Yaksh 1978), the dog (Cohen et al. 1982; Bonath et al. 1984) and nonhuman primates (Yaksh 1978; Bahar et al. 1984). In addition, the continuous epidural infusion of opiates using an implanted pump has been described in the dog (Cohen et ai. 1982) offering the possibility of prolonged analgesia without the necessity of repeated injections of drug through an exteriorized spinal catheter.

\section{Conclusions}

Considerable opportunity exists for the adoption of better methods for the management of pain and distress in animals. Experimental studies in animals and clinical experience in man are likely to continue 
to offer new approaches that can be applied to veterinary clinical practice. Major problems remain, for example, the control of chronic pain, particularly in laboratory animals where the prolonged use of analgesics may interfere with the experimental protocol.

The solution of these and other problems requires both the development of new techniques and the better application of existing knowledge. A change in priorities by all those concerned in the management of animals is required, with considerably greater emphasis being placed on the well-being of the animal. Improved education at all levels is needed to disseminate available knowledge, and to promote a greater awareness of the needs of the animals given over to our care.

Table 1. Analgesic drugs for use in animals.

\begin{tabular}{|c|c|c|c|c|}
\hline & Morphine & Pethidine & Pentazocine & Buprenorphine \\
\hline Mouse & $\begin{array}{l}10 \mathrm{mg} / \mathrm{kg} \mathrm{s} / \mathrm{c} \\
2-4 \text { hourly }\end{array}$ & $\begin{array}{l}20 \mathrm{mg} / \mathrm{kg} \mathrm{s} / \mathrm{c} \mathrm{i} / \mathrm{m} \\
2-3 \text { hourly }\end{array}$ & $\begin{array}{l}10 \mathrm{mg} / \mathrm{kg} \mathrm{s} / \mathrm{c} \\
3-4 \text { hourly }\end{array}$ & $\begin{array}{l}2.0 \mathrm{mg} / \mathrm{kg}^{*} \mathrm{~s} / \mathrm{c} \\
12 \text { hourly }\end{array}$ \\
\hline Rat & $\begin{array}{l}10 \mathrm{mg} / \mathrm{kg} \mathrm{s} / \mathrm{c} \\
2-4 \text { hourly }\end{array}$ & $\begin{array}{c}20 \mathrm{mg} / \mathrm{kg} \mathrm{s} / \mathrm{c} \mathrm{i} / \mathrm{m}^{*} \\
2-3 \text { hourly }\end{array}$ & $\begin{array}{c}10 \mathrm{mg} / \mathrm{kg} \mathrm{s} / \mathrm{c} \\
4 \text { hourly }\end{array}$ & $\begin{array}{c}0.1-0.5 \mathrm{mg} / \mathrm{kg}^{*} \mathrm{~s} / \mathrm{c} \\
12 \text { hourly }\end{array}$ \\
\hline Rabbit & $\begin{array}{c}5 \mathrm{mg} / \mathrm{kg} \mathrm{s} / \mathrm{c} \\
\mathrm{i} / \mathrm{m} 2-4 \text { hourly }\end{array}$ & $\begin{array}{c}10 \mathrm{mg} / \mathrm{kg} \mathrm{s} / \mathrm{c} \mathrm{i} / \mathrm{m}^{*} \\
2-3 \text { hourly }\end{array}$ & $\begin{array}{c}10-20 \mathrm{mg} / \mathrm{kg} \mathrm{s} / \mathrm{ci} / \mathrm{m} \\
4 \text { hourly }\end{array}$ & $\begin{array}{l}0.02-0.05 \mathrm{mg} / \mathrm{kg}^{*} \\
\mathrm{~s} / \mathrm{c}, \mathrm{i} / \mathrm{v} 8-12 \text { hourly }\end{array}$ \\
\hline Guinea Pig & $\begin{array}{c}10 \mathrm{mg} / \mathrm{kg} \mathrm{s} / \mathrm{c} \\
\mathrm{i} / \mathrm{m} 2-4 \text { hourly }\end{array}$ & $\begin{array}{c}20 \mathrm{mg} / \mathrm{kg} \mathrm{s} / \mathrm{c} \mathrm{i} / \mathrm{m} \\
2-3 \text { hourly }\end{array}$ & - & $\begin{array}{c}0.05 \mathrm{mg} / \mathrm{kg} \mathrm{s} / \mathrm{c} \\
8-12 \text { hourly }\end{array}$ \\
\hline Cat & $\begin{array}{c}0.1 \mathrm{mg} / \mathrm{kg} / \mathrm{s} / \mathrm{c}^{\dagger} \\
4 \text { hourly }\end{array}$ & $\begin{array}{c}10 \mathrm{mg} / \mathrm{kg} \mathrm{s} / \mathrm{ci} / \mathrm{m}^{*} \\
2 \text { hourly }\end{array}$ & $\begin{array}{l}8 \mathrm{mg} / \mathrm{kg} \mathrm{i} / \mathrm{p} \\
? 4 \text { hourly }\end{array}$ & $\begin{array}{l}0.005-0.01 \mathrm{mg} / \mathrm{kg}^{*} \\
12 \text { hourly }\end{array}$ \\
\hline Dog & $\begin{array}{c}0.5-5.0 \mathrm{mg} / \mathrm{kg} \dagger \\
\mathrm{s} / \mathrm{c} \mathrm{i} / \mathrm{m} \\
2-4 \text { hourly }\end{array}$ & $\begin{array}{c}10 \mathrm{mg} / \mathrm{kg} \mathrm{s} / \mathrm{c} \mathrm{i} / \mathrm{m}^{*} \\
2-3 \text { hourly }\end{array}$ & $\begin{array}{c}2.0 \mathrm{mg} / \mathrm{kg} \mathrm{i} / \mathrm{m}^{*} \\
4 \text { hourly }\end{array}$ & $\begin{array}{c}0.01-0.02 \mathrm{mg} / \mathrm{kg}^{*} \mathrm{i} / \mathrm{m} \\
\mathrm{s} / \mathrm{c} 12 \text { hourly }\end{array}$ \\
\hline Primate & $\begin{array}{l}1-2 \mathrm{mg} / \mathrm{kg} \mathrm{s} / \mathrm{c} \\
4 \text { hourly }\end{array}$ & $\begin{array}{l}2-4 \mathrm{mg} / \mathrm{kg} \mathrm{i} / \mathrm{m}^{*} \\
3-4 \text { hourly }\end{array}$ & $\begin{array}{c}2-5.0 \mathrm{mg} / \mathrm{kg} \mathrm{i} / \mathrm{m}^{*} \\
4 \text { hourly }\end{array}$ & $\begin{array}{c}0.01 \mathrm{mg} / \mathrm{kg}^{*} \mathrm{i} / \mathrm{m} \mathrm{i}^{\mathrm{v}} \\
12 \mathrm{hourly}\end{array}$ \\
\hline Pigs & $\begin{array}{c}\text { Up to } \\
20 \mathrm{mg} \text { total dose } \dagger\end{array}$ & $\begin{array}{c}2 \mathrm{mg} / \mathrm{kg} \mathrm{i} / \mathrm{m}^{*} \\
4 \text { hourly }\end{array}$ & $\begin{array}{l}2.0 \mathrm{mg} / \mathrm{kg} \mathrm{i} / \mathrm{m}^{\dagger} \\
4 \text { hourly }\end{array}$ & $\begin{array}{c}0.005-0.01 \mathrm{mg} / \mathrm{kg}^{*} \mathrm{i} / \mathrm{m} \\
12 \text { hourly }\end{array}$ \\
\hline Sheep & $\begin{array}{c}\text { Up to } \\
10 \mathrm{mg} \text { total } \\
\text { dose } \mathrm{i} / \mathrm{m} \dagger\end{array}$ & $\begin{array}{c}\text { Up to } \\
200 \mathrm{mg} \text { total } \\
\text { dose } \mathrm{i} / \mathrm{m} \dagger\end{array}$ & - & $\begin{array}{c}0.005 \mathrm{mg} / \mathrm{kg}^{*} \mathrm{i} / \mathrm{m} \\
12 \text { hourly }\end{array}$ \\
\hline
\end{tabular}

Dose rates suggested from published data.

*Clinical experience at the Clinical Research Center, Harrow.

$\dagger$ Recommended dosages in veterinary literature (Lumb and Jones 1984; Green 1979; Hall and Clark 1983). 


\section{References}

Bahar, M., Nunn, J.F., Rosen, M. and Flecknell, P. 1984. Differential sensory and motor blockade after spinal cocaine in the rat and marmoset. Eur. J. Anaes. 1:31-36.

Blumberg, H., Dayton, H.B. and Wolf, P.S. 1968. Analgesic properties of the narcotic antagonist EN-2234A. Pharmacologist. 10:201.

Bonath, K., Gerlach, K. and Gilber, W. 1984. Peridural catheter and its importance for peridural anaesthesia and pain treatment in the dog. Paper presented at the 2nd FELASA symposium, June 1984.

Brown, L.A. In press. The clinical measurement of pain, distress and discomfort in fish. In: The Detection and Relief of Pain in Animals. 2nd British Veterinary Association Animal Welfare Foundation Symposium. London: British Veterinary Association Animal Welfare Foundation.

Camporesi, E.M. and Redick, L.F. 1983. Clinical aspects of spinal narcotics: Post-operative managements and obstetrical pain. Clinical in Anaesthesiology. 1:57-70.

Cohen, A.M., Wood, W.C., Bambert, B.S., Risaliti, A. and Poletti, C. 1982. Continuous canine epidural morphine analgesic with an implanted drug infusion pump. J. Surg Res. 32:32-37.

Cooper, J.E. and Organ, P. 1977. Pentazocine as an analgesic in dogs. Vet. Rec. 101:409.

Cowan, A., Doxey, J.C. and Harry, E.J.R. 1977a. The animal pharmacology of buprenorphine, an oripavine analgesic agent. B.J. Pharm. 60:547-54.

Cowan, A., Lewis, J.W. and McFarlane, I.R. 1977b. Agonist and antagonist properties of buprenorphine, a new antinociceptive agent. B.J. Pharm. 60:537-45.

Davis, L.E. and Donnelly, E.J. 1968. Analgesic drugs in the cat. JAVMA 153:1161-7.

Davison, C., Hertig, D.H. and DeVine, R. 1966. Gastric hemorrhage induced by non-narcotic analgetic agents in dogs. Clin. Pharmacol. Ther. 7:239.

De Vos, V. 1978. Immobilisation of free-ranging wild animals using a new drug. Vet. Rec. 103:64.

Edwards, G.B. In press. Clinical assessment of pain, distress and discomfort in ruminants. In: 2nd British Veterinary Association Animal Welfare Foundation Symposium. The Detection and Relief of Pain in Animals. London: British Veterinary Association Animal Welfare Foundation.

Fahmy, N.R. 1983. Nalbuphine hydrochloride. Clinics in Anaesthesiology. 1:164-7

Fell, D., Chmielewski, A. and Smith, G. 1982. Post-operative analgesia with controlledrelease morphine sulphate: comparison with intramuscular morphine. Br.M.J. 285:92-94

Flecknell, P.A. 1984. The relief of pain in laboratory animals. Laboratory Animals. 18:147-60.

Frederickson, R.C.A. and Smiths, S.E. 1973. Time course of dependence and tolerance development in rats treated with "slow release" morphine suspensions. Res. Comm. Chem. Path. Pharmacol. 5:867-70.

Gentle, M.J. In press. Measurements of pain, distress and discomfort in poultry and other birds. In: 2nd British Veterinary Association Animal Welfare Foundation Symposium. The Detection and Relief of Pain in Animals. London: British Veterinary Association Animal Welfare Foundation.

Green, C.J. 1979. Animal Anaesthesia. London: Laboratory Animals Ltd.

Gustafsson, L., Schildt, B. and Jacobsen, I. 1982. Adverse effects of extradural and intrathecal opiates: report of a nationwide survey in Sweden. Br. J. Anaes. 54:479-85.

Hales, P. 1980. Pruritis after epidural morphine. Lancet. ii:204

Hall, L.W. and Clarke, K.W. 1983 Veterinary Anaesthesia. London: Balliere Tindall.

Heel, R.C., Brogden, R.N., Speight, T.M. and Avery, G.S. 1978. Butorphanol: a review of its pharmacological properties and therapeutic efficacy. Drugs, 16:473-505.

Heel, R.C., Brogden, R.M., Speight, T.M. and Avery, G.S. 1979. Buprenorphine: a review of its pharmacological properties and therapeutic efficacy. Drugs. 17:81-110. 
House, R.W. 1979. Analgesic effectiveness of the narcotic agonist-antagonists. B.J. Clin. Pharm. 7:2975-3085.

Kehlet, H. 1978. Influence of epidural anaesthesia on the endocrine-metabolic response to surgery. Acta. Anaesth. Scand. (Suppl) 70:39-42.

Laska, F.J. and Fennessy, M.R. 1978. Induction of physical dependence on cyclazocine and pentazocine in the rat. Eur. J. Pharmacol. 48:57-65.

Lumb, W.V. and Jones, E.W. 1984. Veterinary Anaesthesia. 2nd Edition, Philadelphia: Lea and Febiger.

McGinity, J.W. and Mehta, C.S. 1978. Preparation and evaluation of a sustained morphine delivery system in rats. Pharm. Biochem. Behav. 9:705-8.

Mather, L.G. 1983. Pharmacokinetic and pharmacodynamic factors influencing the choice, dose and route of administration of opiates for acute pain. Clinics in Anaesthesiology. $1: 17-40$.

Mather, L. and Mackie, J. 1983. The incidence of post-operative pain in children. Pain. 15:271-82.

Melzack, R. and Dennis, S.G. 1980. Phylogenetic evolution of pain expression in animals. In: Kosterlitz, H.W. and Tererius, L.Y., eds. Pain and Society. Holland: Elsevier.

Moloney, V. In press. Procedures painful in man are painful in animals-true or false? In: 2nd British Veterinary Association Animal Welfare Foundation Symposium. The Detection and Relief of Pain in Animals. London: British Veterinary Association Animal Welfare Foundation.

Morton, D.B. and Griffiths, P.H.M. 1985. Guidelines on the recognition of pain, distress and discomfort in experimental animals and an hypothesis for assessment. Vet. Rec. 116:431-6.

Morton, D.B. In press. The recognition of pain, distress and discomfort in small laboratory mammals and its assessment. In: 2nd British Veterinary Association Animal Welfare Foundation Symposium. The Detection and Relief of Pain in Animals. London: British Veterinary Association Animal Welfare Foundation.

Neumann, G., Erhardt, W., Oberhuber, B., Fritsch, R. and Blumel, G. 1980. A new highly potent and short acting analgesic, carfentanil (R33 799), in combination with the hypnotic agent etomidate (R26 490) as a method of anaesthesia in guinea pigs. Research in Experimental Medicine (Berlin) 177:135.

Niemegeers, C.J.E. 1977. R39 209, a potent and very short acting morphine-like analgesic. Research Report N15340. Janssen Pharmaceutica.

Oldham, J. In press. Clinical measurement of pain, distress and discomfort in pigs. In: 2nd British Veterinary Association Animal Welfare Foundation Symposium. The Detection and Relief of Pain in Animals. London: British Veterinary Association Animal Welfare Foundation.

Pearl, J., Stander, H. and McKean, D.B. 1969. Effects of analgesics and other drugs on mice in phenylquinone and rotarod tests. J. Pharmac. Exper. Ther. 167:9-13.

Pippi, N.L. and Lumb, W.V. 1979. Objective tests of analgesic drugs in ponies. Am. J. Vet. Res. 40:1082-6.

Pircio, A.W., Gylys, J.A., Cavanagh, R.L., Buyniski, J.P. and Bierwagen, M.E. 1976. The pharmacology of butorphanol, a 3, 14-dihydroxymorphinan narcotic antagonist analgesic. Arch. Int. Pharm. 220:231-57.

Reiz, S., Ahlin, J. and Ahrenfeldt, B. 1981. Epidural morphine for post-operative pain relief. Acta. Anaes. Scand. 25:111-4.

Robertson, J.T., Muir, W.W. and Sams, R. 1981. Cardiopulmonary effects of butorphanol tartarate in horses. Am. J. Vet. Res. 42:41-44.

Schauffler, A.F. 1969. Better equine restraint. Mod. Vet. Pract. 50:46-49.

Silver, I.A. In press. The clinical measurement of pain, distress and discomfort in horses. In: 2nd British Veterinary Association Animal Welfare Foundation Symposium. The Detection and Relief of Pain in Animals. London: British Veterinary Association Animal Welfare Foundation. 
Smith, G. 1984. Post-operative Pain. In: Lunn, J.N. ed. Quality of Care in Anaesthetic Practice. London: McMillan Press Ltd.

Taylor, P.M. and Houlton, J.E.F. 1984. Post-operative analgesia in the dog: a comparison of morphine, buprenorphine and pentazocine. J. Small Anim. Pract. 25:437-51.

Taylor, P.M. 1985. Analgesia in the dog and the cat. In Practice. 7:5-13.

Taylor, P.M. In press. Clinical measurement of pain, distress and discomfort in dogs and cats. In: 2nd British Veterinary Association Animal Welfare Foundation Symposium. The Detection and Relief of Pain in Animals. London: British Veterinary Association Animal Welfare Foundation.

Tribe, G.W. In press. Clinical measurement of pain, distress and discomfort in Simian Primates. In: 2nd British Veterinary Association Animal Welfare Foundation Symposium. The Detection and Relief of Pain in Animals. London: British Veterinary Association Animal Welfare Foundation.

Uvarov, $\mathrm{O}$. In press. Ethical conceptions and the role and the problems of the veterinary profession in the alleviation of pain. In: 2nd British Veterinary Association Animal Welfare Foundation Symposium. The Detection and Relief of Pain in Animals. London: British Veterinary Association Animal Welfare Foundation.

Vickers, M.D., Schnieder, H. and Wood-Smith, F.G. 1984. Drugs in Anaesthetic Practice. Sevenoaks, England: Butterworths.

Wilkinson, G.T. 1984. Toxicology. In: Wilkinson, G.T. ed. Diseases of the Cat and Their Management. London: Blackwell Scientific Pub.

Yaksh, T.L. 1978. Analgetic actions of intrathecal opiates in cat and primate. Brain Res. 153:205,210

Yaksh, T.L. 1981. Spinal opiate analgesia: characteristics and principles of action. Pain. 11:293-346.

Yaksh, T.L. 1983. The principle behind the use of spinal narcotics. Clinics in Anaesthesiology. 1:219-32.

Yaksh, T.L. and Rudy, T.A. 1976. Chronic catheterisation of the spinal subarachnoid space. Physiol. Behav. 17:1031-6.

Yoxall, A.T. 1978. Pain in small animals -its recogniton and control. J. Small Anim. Pract. 19:423-38. 